\title{
A interseccionalidade dos povos bantu e suas afroperspectivas no chão da escola, na disciplina de filosofia
}

\author{
The intersectionality of the bantu people and their \\ afroperspectives on the school floor, in the subject of \\ philosophy
}

\begin{abstract}
Wudson Guilherme de Oliveira
Mestrando em Educação, Contextos Contemporâneos e Demandas Populares PPGEDUC, pela UFRRJ (Universidade Federal Rural do Rio de Janeiro). Desenvolve vivências como professor de História, Filosofia, Sociologia e Geografia nos Anos Finais do Ensino Fundamental, Ensino Médio, EJA, Palestrante e Oficineiro. Possui de modo voluntário um "Projeto de sensibilização sobre a história africana, indígena e afro-brasileira através das literaturas nos espaços informais de educação"

E-mail:wudafrica@gmail.com
\end{abstract}

\section{RESUMO}

Este artigo tem como objetivo apresentar reflexões da Filosofia Africana (LOPES e SIMAS, 2020) acerca da ancestralidade, da história, cultura e linguística dos Povos Bantu (LWANGA-LUNYIIGO, e VANSINA, 2010) e a necessidade da implementação da Lei Federal 10.639/2003, bem como do compromisso para que se consolide a sua efetivação no Ensino de Filosofia (NOGUEIRA, 2011). Para o sucesso desta proposta, trabalhamos os valores morais e norteadores da Ética e as questões ligadas ao Respeito com uma turma do 1ำ Ano do Ensino Médio, composta por Alunados de jovens Pretos (as), Pardos (as) e Brancos (as) inseridos em uma instituição privada de educação na Baixada Fluminense, cidade metropolitana do Rio de Janeiro, onde evidenciamos uma Pedagogia Antirracista (GOMES, 2017) e Decolonial (WALSH, 2013) a partir das pesquisas de Filósofos e Filosofas Afro-americanos, Africanos (ASANTE, 2009) e Afrobrasileiros, que produziram pensamentos filosóficos amparados na afroperspectiva. A metodologia utilizada foi gerada a partir de Oficinas, Rodas de Diálogos, Exposições de Livros de Literaturas Africanas, Indígenas e AfroBrasileiros, apresentações sensibilizadoras de vídeos, textos e slides afrocentrados, onde serviram de subsídio para propor as discussões na Luta contra o Racismo. Graças a estas dinâmicas, foi possível descolonizar olhares eurocêntricos, racistas, xenofóbicos, machistas, homofóbicos entre outros, além de aumentar as estimas de Alunos Negros, proporcionar e construindo estratégias sólidas para a contribuição da valorização e a construção das identidades negras em prol da redução do Racismo.

Palavras-chave: Filosofia Africana, Bullying, Racismo, Decoloniedade. 


\section{ABSTRACT}

This article aims to present reflections on African Philosophy (LOPES and SIMAS, 2020) about the ancestry, history, culture and linguistics of the Bantu People (LWANGA-LUNYIIGO, and VANSINA, 2010) and the need to implement the Federal Law 10.639/2003, as well as the commitment to consolidate its effectiveness in the Teaching of Philosophy (NOGUEIRA, 2011). For the success of this proposal, we work on the moral and guiding values of Ethics and issues related to Respect with a class of the 1st Year of High School, made up of Black, Brown and White students. in a private educational institution in Baixada Fluminense, a metropolitan city of Rio de Janeiro, where we evidenced an Antiracist (GOMES, 2017) and Decolonial (WALSH, 2013) Pedagogy from the research of African-American and African Philosophers (ASANTE, 2009) and Afro-Brazilians, who produced philosophical thoughts supported by an Afroperspective. The methodology used was generated from Workshops, Rounds of Dialogs, Exhibitions of African, Indigenous and Afro-Brazilian Literature Books, sensitizing presentations of Afro-centered videos, texts and slides, which served as a subsidy to propose discussions in the Fight against Racism. Thanks to these dynamics, it was possible to decolonize Eurocentric, racist, xenophobic, sexist, homophobic views, among others, in addition to increasing the esteem of Black Students, providing and building solid strategies for the contribution of valorization and the construction of black identities in favor of reduction of Racism.

Keywords: African Philosophy; Bullying; Racism; Decolonity.

\section{PENSAMENTOS INCIPIENTES}

"A educação é o principal elo que pode fazer ser propagada e disseminada as intensões das Leis Federais 10.639/03 e $11.645 / 08$, valorizando assim as histórias e os feitos dos grupos africanos que aportaram no Brasil, dos seus descendentes afros-brasileiros e os indígenas em nossa sociedade, contribuindo de forma positiva no processo de eliminação das discriminações, a redução do racismo e a exclusão das desigualdades".

É de imprescindível relevância, recapitular que em exatamente 18 anos atrás, no mês de janeiro do ano de 2003, ocorreu a sanção da implementação da Lei Federal 10.639/20031 "Ela simbolizava, simultaneamente, um ponto de

\footnotetext{
${ }^{1}$ Em 11 de Março de 2008 a Lei 10.639/2003 foi substituída pela criação da Lei 11.645/2008 que torna obrigatório, também, o ensino ligado à História e Cultura dos Povos Indígenas nos currículos oficiais da educação nacional.
} 
chegada das lutas antirracistas no Brasil e um ponto de partida para a renovação da qualidade social da educação brasileira" (BRASIL, 2009, p. 9), que transmutou o Artigo 26 A da Lei de Diretrizes e Bases da Educação Nacional (LDBEN), onde estabeleceu a indispensabilidade do ensino de História e Cultura Africana e Afro-brasileira "Registro da história não contada dos negros brasileiros, tais como os remanescentes de quilombos, comunidades e territórios negros urbanos e rurais" (BRASIL, 2004, p. 13-14) no Ensino Básico. A Lei Federal 10.639/2003 surge com o intuito de remodelar a antecedente de $\mathrm{n}^{0}$ 9.394, de 20 de dezembro de 1996, afirmada e expandida nos seguintes artigos 26-A, 79-A e 79-B.

A promulgação da Lei Federal 10.639/2003, foi uma conquistas ocorrida graças às virtudes dos diversos protagonismos dos Movimentos Sociais Negros no Brasil, que não se cansaram de reivindicar durante décadas, com seus clamores sensibilizados, para que se tornasse possível estabelecer um ensino potente nos currículos do sistema de ensino brasileiro, que contemplassem os estudo das Histórias e Culturas Africanas e Afro-brasileiras.

Sobre o respeito do protagonismo dos Movimentos Negros $^{2}$ em relação aos processos das promoções das equidades raciais no Brasil, Nilma Lino Gomes afirma:

\begin{abstract}
Uma coisa é certa: se não fosse a luta do Movimento Negro nas suas mais diversas formas de expressão e de organização (...) muito do que - Brasil sabe atualmente sobre a questão racial e africana, não teria acontecido. E muito do que hoje se produz sobre a temática racial e africana, em uma perspectiva crítica e emancipatória não teria sido construído. E nem as políticas de promoção da igualdade racial teriam sido construídas e implementadas. (...) A obrigatoriedade do estudo da história e da cultura afro-brasileira e africana nas escolas públicas e particulares de educação básica não teriam se transformado em realidade, ajudando a todos nós, brasileiras e brasileiros, de todo e qualquer grupo étnico-racial a superar a nossa ignorância sobre o racismo e seus efeitos nefastos, como também a reconhecer o
\end{abstract}

\footnotetext{
${ }^{2}$ A respeito dos processos de mobilizações e organização do movimento negro no Brasil referidos ao século passado e atual, podemos nos portar em referenciais como: Antônio Liberac C. S. Pires; Amilcar Araújo Pereira, 2007; Amauri Mendes Pereira, 2008; Clóvis Moura, 1983; Florestan Fernandes, 1978; Kabengele Munanga, 1996; Marcos Antônio Cardoso, 2011; Nilma Lino Gomes, 2017; Roger Bastide, 1972; Sales Augusto dos Santos, 2005, entre outros.
} 
protagonismo das negras e dos negros, que representam $53 \%$ da população que vive e constrói o nosso país (GOMES, 2017, p. 18-19).

Embora já se tenham passado 18 anos da promulgação da Lei Federal 10.639/2003, podemos refletir, que para ela avançar e funcionar de forma eficaz e ativa em nossa sociedade educacional, e em muitos outros espaços, ainda existem alguns inconvenientes que vem sendo denunciadas pelos educadores e pelo Movimento Negro, que indicam críticas sobre os embaraços que acercam a falta de Cursos de Formação Pedagógica sobre as perspectivas das Leis Federais 10.639/2003 e 11.645/2008, sem deixar de mencionar os desprovimentos de materiais, didáticos e paradidáticos que ainda não estão presentes nas salas de aula "o racismo imprime marcas negativas na subjetividade dos negros e também na dos que os discriminam" (Parecer CNE/CP 3/2004), provocando à não subsidiar os Professores regentes.

Sobre o protagonismo da Lei Federal 10.639/2003, ainda não está sendo valorizada e reconhecida por grande parte dos Profissionais da Educação e intelectuais, impedindo de forma desestruturante a incorporação dos referentes conteúdos que acercam as Histórias e Culturas Africanas, dos Afro-brasileiros e dos Grupos Indígenas, nos currículos da Educação Básica para a superação do racismo "ideologia de superioridade racial que tende a beneficiar as pessoas brancas" (MALOMALO, 2018, p. 491).

Assim, estas ações afirmativas "conjunto de políticas públicas e privadas de caráter compulsório, facultativo ou voluntário, concebidas com vista ao combate à discriminação racial, de gênero e de origem nacional, bem como para corrigir os efeitos presentes da discriminação praticada no passado" (GOMES, 2001, p. 40) visavam ultrapassar as tentativas de reparações e oportunidades de igualdades individuais, no qual aparentemente não integra toda a falta de ações imbuídas com as temáticas do Artigo 26 - A da LDBEN, para Cursos e Oficinas Pedagógicas para Educadores.

Com relação aos preceitos da contrariedade em encontrar materiais, precisamos levantar alguns indagações permanentes sobre estes argumentos, pois nos últimos 18 anos da exposição da Lei Federal do Artigo 26 - A da LDBEN, foram produzidos e confeccionados uma infinidade de Livros, Vídeos, Revistas, 
Blogs e muitos outros matérias, para a exaltação das Culturas e Histórias das Áfricas, Educação das Relações Étnico-Raciais, Políticas de Igualdade Racial ${ }^{3}$, Diáspora Afrodescendente "[...] sua adoção se insere no âmbito das reparações reivindicadas pelos movimentos negros, o termo só é aplicável aos descendentes das vítimas diretas ou indiretas do escravismo dos séculos XVI a XIX (LOPES, 2011, p. 57), Juventude Negra, Questões Quilombolas, Africanidades, Saúde da População Negra e Antirracismo.

Figura 1. Slide sobre a importância das Leis Federais no Chão da Escola.

Arte: Wudson Guilherme de Oliveira (professor).

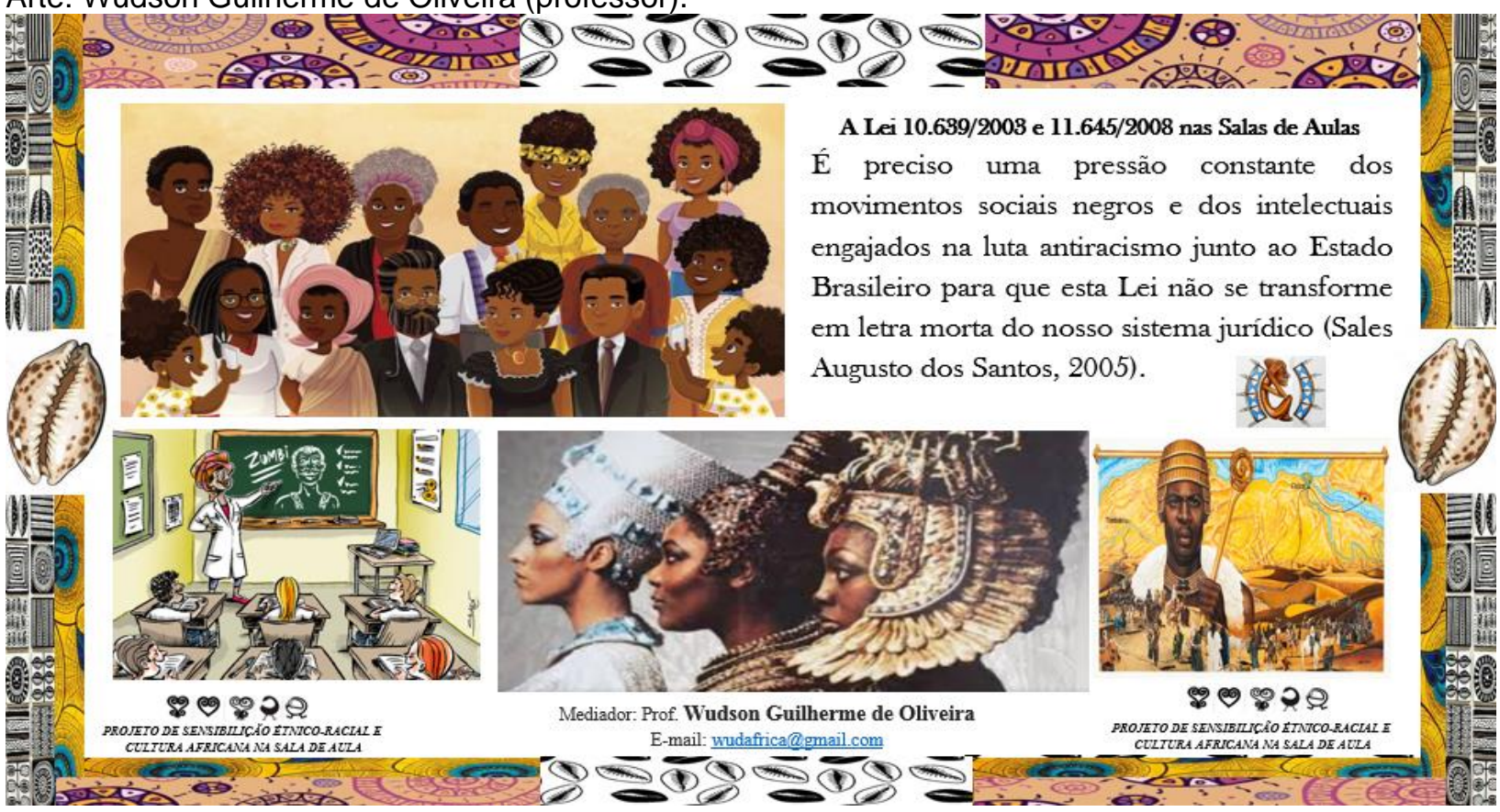

Em consequência, também foram germinadas novas discussões acaloradas que questionaram e dinamizaram os conhecimentos sobre Desigualdade Racial, Violência, Preconceito, Ações Afirmativas, Gênero, Racismo, Intolerância Religiosa contra os adeptos das religiões afro-brasileiras, e outras intervenções epistemológicas e teóricas das ciências sociais, humanas,

\footnotetext{
3 “[...] raça é uma construção política e social. É a categoria discursiva em torno da qual se organiza um sistema de poder socioeconômico, de exploração e exclusão, ou seja, o racismo. Todavia, como prática discursiva, o racismo possui uma lógica própria. Tenta justificar as diferenças sociais e culturais que legitimam a exclusão racial em termos de distorções genéticas e biológicas, isto é, na natureza" (HALL, 2003, p. 69).
} 
jurídicas e da saúde, incluindo, as produções críticas das teorias do século XIX, que ainda são presentes no imaginário pedagógico, teórico e social (GOMES, 2017).

Outras problemáticas ainda estão sendo encontradas para o acesso aos materiais confeccionados, e a promoção da existência desses materiais, e por último, mais não menos importante, a ausência de estimulo e interesse de uma parcela de Profissionais de Educação, que atrelam a implementação das Leis Federais, apenas aos Professores Afro-brasileiros "qualitativo do indivíduo brasileiro de origem africana e de tudo que Ihe diga respeito. Relativo, ao mesmo tempo, a África e ao Brasil, como o indivíduo brasileiro de ascendência africana" (LOPES, 2011, p. 56), ou mesmo apenas aos Professores que lecionam aulas das Disciplina de História, Literatura, Geografia, Sociologia ou Artes.

Seguindo a linha de pensamento, preferencial em três culminâncias pedagógicas, nas seguintes datas comemorativas anuais: 19 de Abril ${ }^{4}, 13$ de Maio ${ }^{5}$ e na penúltima semana do mês de Novembro $^{6}$, como mera efetivação desimpedida sobre as Histórias e Culturas do Negro, como método de cumprimento das Leis Federais 10.639/03 e 11.645/2008 nos Espaços de Educação.

É de grande importância também pontuar, que todas as negativas à anterior, encontramos também outros obstáculos propiciados por uma quantidade expressiva de Professores e outros Agentes Educacionais, que se

\footnotetext{
${ }^{4}$ Nesta data é comemorado o "Dia Nacional do Índio". Onde alguns professores caracterizam os seus alunos com única pena grande na cabeça, rosto pintado com tinta guache branca e tanga de papel pardo com um machado cruzado. Atualmente, os grupos indígenas tentam resignificar em "Dia da Conscientização para a Questão Indígena", como forma de defesa da sua cultura e dos direitos de seus povos.

${ }^{5}$ Vale destacar que durante muitos anos, as questões que acercavam as Histórias e Culturas dos Negros no Brasil, só eram lembradas de modo educativo ou cívico, apenas na data do 13 de maio, dia da assinatura da Lei Áurea, em 1888, onde declarou extinta a escravidão no Brasil. Esta data era conhecida como o "Dia da Libertação dos Escravos", dia que se exaltavam apenas uma "dita" benevolência de uma princesa, sem se discutir as lutas e resistências dos grupos negros para a sua própria libertação. O Movimento Negro tem interpretado esta data como "Dia Nacional de Luta contra o Racismo", de modo à reeducar e construir novos diálogos pela igualdade e representatividade.

${ }^{6}$ No Estado do Rio de Janeiro, é decretado como feriado o dia 20 de novembro, data da morte do líder quilombola Zumbi dos Palmares, estabelecido com o "Dia da Consciência Negra" sancionada pela Governadora Benedita da Silva pela LEI № 4007, DE NOVEMBRO DE 2002.
} 
recusam em trabalhar às discussões que são atreladas as Histórias e Culturas Africanas e Afro-brasileiras.

Algumas vezes estas resistências, estão atreladas pela falta de sensibilidade dos colegas Professores, que estão amparados à repulsa em trazer para dentro da sala de aula, debates potentes sobre tais controvérsias, como por exemplo as perspectivas ligadas à Discriminação, Preconceito, Racismo, Branquitude", Religiosidade, Interseccionalidade ${ }^{8}$ "Ela trata especificamente da forma pela qual o racismo, o patriarcalismo, a opressão de classe e outros sistemas discriminatórios criam desigualdades básicas que estruturam as posições relativas de mulheres, raças, etnias, classes e outras" (CRENSHAW, 2002, p. 177), Branquidade entre outras, devido ao sentimento de despreparo dos Professores e Profissionais Educacionais, em relação ao domínio das temáticas, ou mesmo a indisposição em promover reflexões (des)construídas e (des)colonizadoras sobre os grupos africanos, indígenas e as suas diásporas africanas no Brasil.

\section{PROBLEMAS DA NÃO IMPLEMENTAÇÃO DAS LEIS NO CHÃO DA} ESCOLA

Em uma instituição privada de Educação Básica, em um município da Baixada Fluminense, região metropolitana do Rio de Janeiro, foram planejadas, preparadas e realizadas de modo solitário "Aulas/Oficinas" de modo emergencial para uma turma do $1^{\circ}$ Ano do Ensino Médio, nas aulas da Disciplina de Filosofia.

\footnotetext{
${ }^{7}$ A branquitude é compreendida como um sistema de valores e comportamentos que toma o ser branco como "o modelo universal de humanidade", o representante de todas as pessoas. Esses valores levam a uma espécie de "cegueira social", fazendo com que grande parte das pessoas brancas não consiga enxergar a dor das pessoas que enfrentam discriminação étnicorracial. Buscar maiores conhecimentos em "Aqui ninguém é branco: hegemonia branca no Brasil", de Liv Sovik.

8 A interseccionalidade foi um termo cunhado no ano de 1989, pela teórica feminista estadunidense Kimberlé Crenshaw (1991). Em suas primeiras reflexões escritas, a autora via a interseccionalidade como uma "metáfora" e em seus textos posteriores Kimberlé Crenshaw passou a apontá-los como uma "categoria provisória". Para saber mais, buscar em: "Mapping the margins: intersectionality, identity politics, and violence against women of color" de Kimberlé Williams Crenshaw.
} 
Não achamos pertinente revelar o nome da instituição de ensino onde ocorreram os entraves em questão. Assim, decidimos dar o nome fictício de "Complexo Educacional Laudelina de Campos Mello9 "Nina, lutas e conquistas no Brasil'”', para assim, homenagear a heroína afro-brasileira, proteger o bom andamento da pesquisa acadêmica e a integridade do espaço de educação, que sempre se declarou como uma instituição de ensino "NÃO RACISTA", que ocorrendo inúmeras ocorrências desajustadas, atreladas às tensões do Bullying ${ }^{10}$ e a "brincadeirinhas inocentes" de adolescentes.

Ao trocar ideias com alguns Alunos (as) e ouvir os relatos das vítimas, que estavam sofrendo frequentemente o "Bullying", me senti obrigado a fazer a leitura dos registros, que me foi possível, observar e analisar, que todas as "piadinhas e brincadeirinhas" ditas como inocentes, nunca foram confrontadas ou mesmo tomadas postura alguma, pelos Coordenadores e Administradores do "Complexo Educacional Laudelina de Campos Mello "Nina, lutas e conquistas no Brasil'”, Nesse ambiente, às ocorrências não estavam atreladas à violência física, mais em registros contendo xingamentos, apelidos, expressões, comparações desrespeitosas, em relação a aparência física, e outras características, tais como, por exemplo: "Seu cabelo é uma bucha de canhão!", "King Kong com peruca de esponja!", "Beiço com picada de abelha!", "Deixa de ser burro, macaco (a)!".

\footnotetext{
9 Vale destacar que Laudelina de Campos Mello, também conhecida com o cognome Nina, nascida em Poços de Caldas, MG, em 12 de outubro de 1904. Sobrinha e neta de escravizados, com 20 anos de idade se mudou para a cidade de Santos, SP, onde com o tempo se integrou a uma facção da Frente Negra Brasileira, Teatro Experimental do Negro (TEN) e também foi presidente da Associação das Empregadas Domésticas. Já nos anos 50, na cidade de Campinas, SP, lutou contra as artimanhas do racismo dentro e fora do mercado de trabalho, onde criou o Concurso Pérola Negra de Campinas. Em 1961 fundou a Associação Profissional Beneficente das Empregadas Domésticas, para defender os direitos das empregadas domésticas. No ano de 1988, a associação foi elevada à categoria de Sindicato dos Trabalhadores Domésticos. Sua luta no movimento negro e feminista, foi primordial para a categoria da conquista do direito à Carteira de Trabalho e à Previdência Social, além de outras iniciativas potentes. Nina faleceu aos 86 anos na cidade de Campinas, SP, no $22^{\circ}$ dia do mês da Abolição da Escravatura do ano de 1991. Para saber mais, consultar em Francisco Lima Neto "Laudelina: Laudelina de Campos Melo" (Campinas, SP: Mostarda, 2021).

10 Beaudoin e Taylor afirmam que "Compreende todas as formas de atitudes agressivas, realizadas de forma voluntária e repetitiva, que ocorre, sem motivação evidente, adotadas por um ou mais estudantes contra outro(s), causando dor e angustia e realizada dentro de uma relação desigual de poder" (BEAUDOIN e TAYLOR, 2006).
} 
Ao fazer alguns questionamentos aos Coordenadores e Professores, percebi o desconhecimento de alguns, e um racismo total de outros. Desse modo, planejei um Projeto Pedagógico para ampliar e compartilhar os conhecimentos, que fora apresentado à Coordenação Escolar, da instituição de ensino, que recebeu e analisou o projeto em questão.

Porém não foi aprovado, por não se tratar de questões tão pertinentes e urgente, pois o "Complexo Educacional Laudelina de Campos Mello "Nina, lutas e conquistas no Brasil'”, não compactuava com algo que não existia, inclusive como a instituição seria racista, se ela possuía em seu quadro de funcionários dois Professores Negros e as "Tias da limpeza da escola".

Com um olhar e postura mais sensibilizadoras e amparadas nas perspectivas afrocentradas, cheguei à conclusão que o "Complexo Educacional Laudelina de Campos Mello "Nina, lutas e conquistas no Brasil"',", estava reproduzindo de modo impróprio, práticas amparadas no racismo institucional e no racismo estrutural "é o racismo que extrapola as relações interpessoais e ocorre à revelia das boas intenções individuais, implicando o comprometimento dos resultados de planos e metas de instituições, gestões administrativas e de governo" (ARAÚJO, TOLENTINO e SILVA, 2018, p. 256) fundamentadas ao racismo, praticadas pelos Alunos (as).

No entanto, estas práticas algumas vezes, também é apoiadas e legitimadas pelos Professores e Coordenadores Pedagógicos, para com os seus Alunos (as) estudantes Pretos e Pardos, utilizando também em pleno século XXI às perspectivas amparadas na meritocracia, agravando assim, as desigualdades e gerando injustiças, mantendo as exclusões fundadas em preconceitos e na manutenção dos privilégios, para os grupos sempre privilegiados acreditavam a todo o tempo no mito da democracia racial ${ }^{11}$.

Ao ter a certeza do que estava ocorrendo, e com o propósito de contribuir com um ensino amparado nas indagações firmadas na resistência

11 Nas palavras de Nilma Lino Gomes (2010) O mito da democracia racial pode ser compreendido, como uma corrente ideológica que pretende negar a desigualdade racial entre brancos e negros no Brasil como fruto do racismo, afirmando que existe entre estes dois grupos raciais uma situação de igualdade de oportunidade e de tratamento. 
afroperspectivista "O termo afroperspectivista tem um sentido simples, O conjunto de pontos de vista, estratégias, sistemas e modos de pensar e viver de matrizes africanas" (NOGUEIRA, 2012, p. 147) e inspirado nas questões antirracista, transgressora e decolonial ${ }^{12}$, em prol da promoção do Artigo $26 \mathrm{~A}$ da LDBEN, assim, surge a ideia de criar as "Aulas/Oficinas" pedagógicas intitulada "A INTERSECCIONALIDADE DOS POVOS BANTU E SUAS AFROPERSPECTIVA NO ENSINO DE FILOSOFIA NO CHÃO DA ESCOLA" como uma maneira de preservar e promover a igualdade racial e a redução do racismo nesta instituição privada de educação e em outros ambientes escolares na cidade do Rio de Janeiro e adjacências.

Figura 2. Slide da Aula/Oficinas sobre a Interseccionalidade dos Povos Bantu. Arte: Wudson Guilherme de Oliveira (professor).

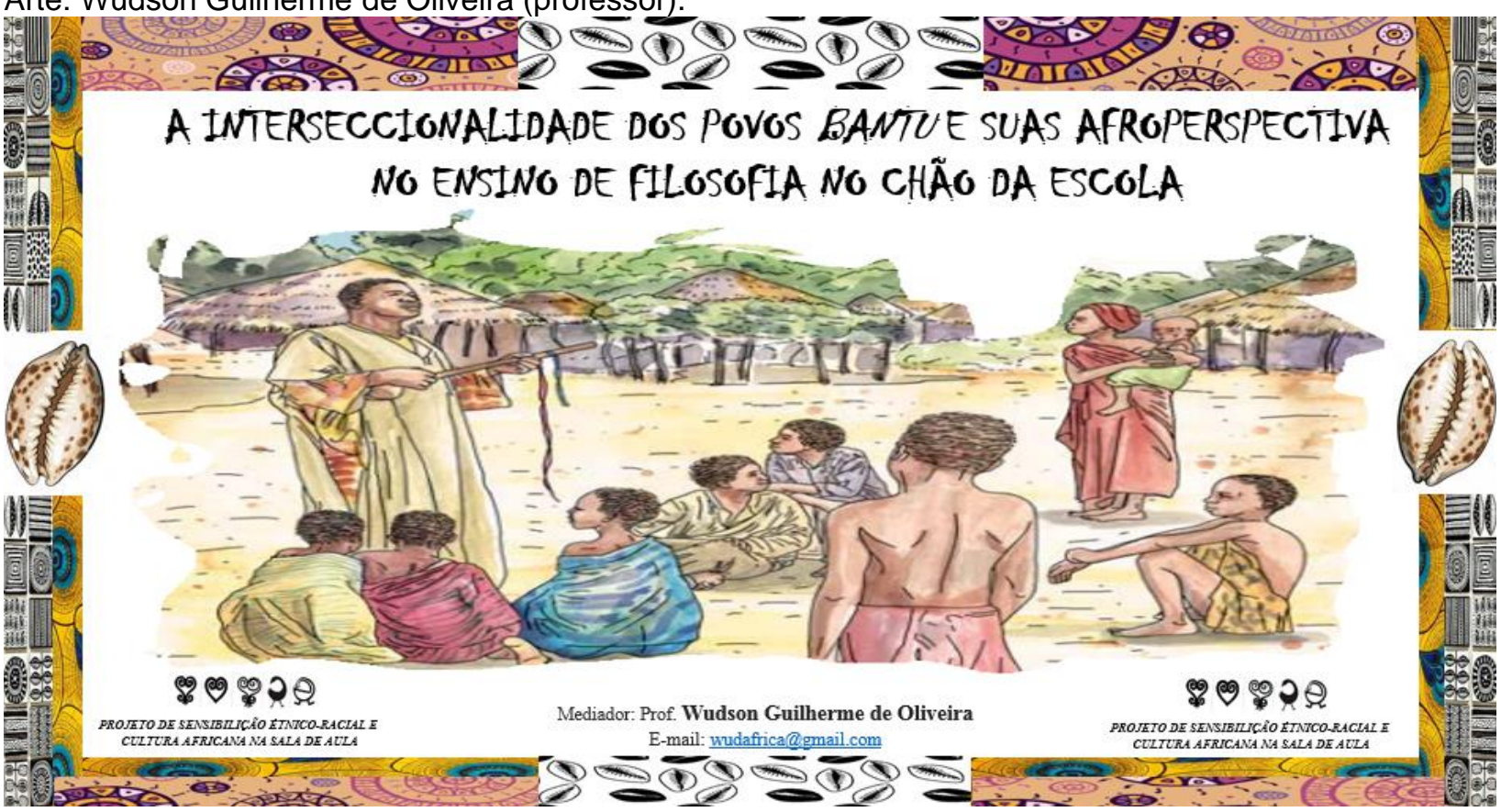

A ação afirmativa foi realizada de modo clandestino, com inspirações na implementação da Lei Federal 10.639/03 e 11.645/08, na resistência de uma

${ }^{12}$ A ativista e pesquisadora Catherine Walsh (2013) foi quem delimitou a referida abordagem por sugerir práticas insurgentes no processo de formação escolarizada, no entanto, também, em outros espaços de conhecimento. Onde se destaca a publicação "Pedagogias Decoloniais: práticas insurgentes de resistir, (re)existir y (re)vivir", livro organizado por ela no ano de 2013. 
Educação Étnico-Racial, na interdisciplinaridade para valorizar a ancestralidade negra, com vistas na trajetória e conjuntura atual dos afro-brasileiros.

Objetivando desse modo, que todos os participantes "Negros" e os "Não Negros" envolvidos na atividade, se sentissem partes importantes desta ação afirmativa para a promoção ao respeito e a autoestima dos afrodescendentes, em prol de uma Educação Étnico-Racial no combate à amenização do Racismo.

\section{AS AULAS TRANSGRESSORA NO CHÃO DA ESCOLA}

Com a intenção de implementar a Lei Federal 10.639/03 e 11.645/08, e as suas perspectivas que acercam as Histórias e Culturas Africanas, Indígenas e Afro-brasileira, para que sejam incorporados nos conteúdos curriculares do Ensino de Filosofia, para a turma do 1ำ Ano do Ensino Médio da Educação Básica, decidi trabalhar com os (as) Alunos (as), utilizando perspectivas da Filosofia Africana ${ }^{13}$ "Ela está presente em todas as discussões a respeito do status filosófico de pensadores e pensadoras do continente africano" (NOGUEIRA, 2014, p. 72) e inspirados nas reflexões de alguns Filósofos (as) e Intelectuais Africanos (as), Afro-americanos (as) e Afro-brasileiros (as), com o intuito e o desafio de se debruçar em pensamentos filosóficos demarcados por repertórios africanos, afrodiaspóricos, indígenas e ameríndios, de modo libertador, transgressor e (des)colonizado.

A estrutura metodológica foi diferentemente de outras Aulas da Disciplina de Filosofia convencionais, convidamos os (as) Alunos (as) à repensarem sobre novos olhares possíveis, para o ensino e saberes de Filosofia. Não de modo ocidental e tradicional, amparado na superioridade do continente europeu e nos pensadores filosóficos gregos, mais sim, à partir da apresentação de determinados conceitos de alguns intelectuais da contemporaneidade como

\footnotetext{
${ }^{13} \mathrm{Em}$ relação aos filósofos que exploram reflexões da Filosofia Africana com uma abordagem filosófica afroperspectivista, podemos nos portar em referenciais como: Abdias do Nascimento, 2002; Cheikh Anta Diop, 1967; Joseph Omoregbe, 1998; Kwame A. Appiah, 1997; Mogobe Ramose, 2011; Paul Hountondji, 2010, Renato Nogueira, 2014, entre outros.
} 
Henry Odera Oruka, Djamila Ribeiro ${ }^{14}$ (2019), Séverine Kodjo-Grandvaux, Léopold Sédar Senghor, Frantz Fanon ${ }^{15}$ (2008), Souleymane Bachir Diagne, Abdias Nascimento, Kwasi Wiredu, Kwame Anthony Appiah, Molefi Kete Asante $^{16}$ (2009), Léonce Ndikumana, Jean Bosco Kakozi, Renato Nogueira ${ }^{17}$ (2014) entre outros (as) pensadores (as) potentes.

Figura 3. Slide sobre os "Filósofos (as) e Pensadores afrocentrados e decoloniais". Fonte e Arte: Wudson Guilherme de Oliveira (professor).

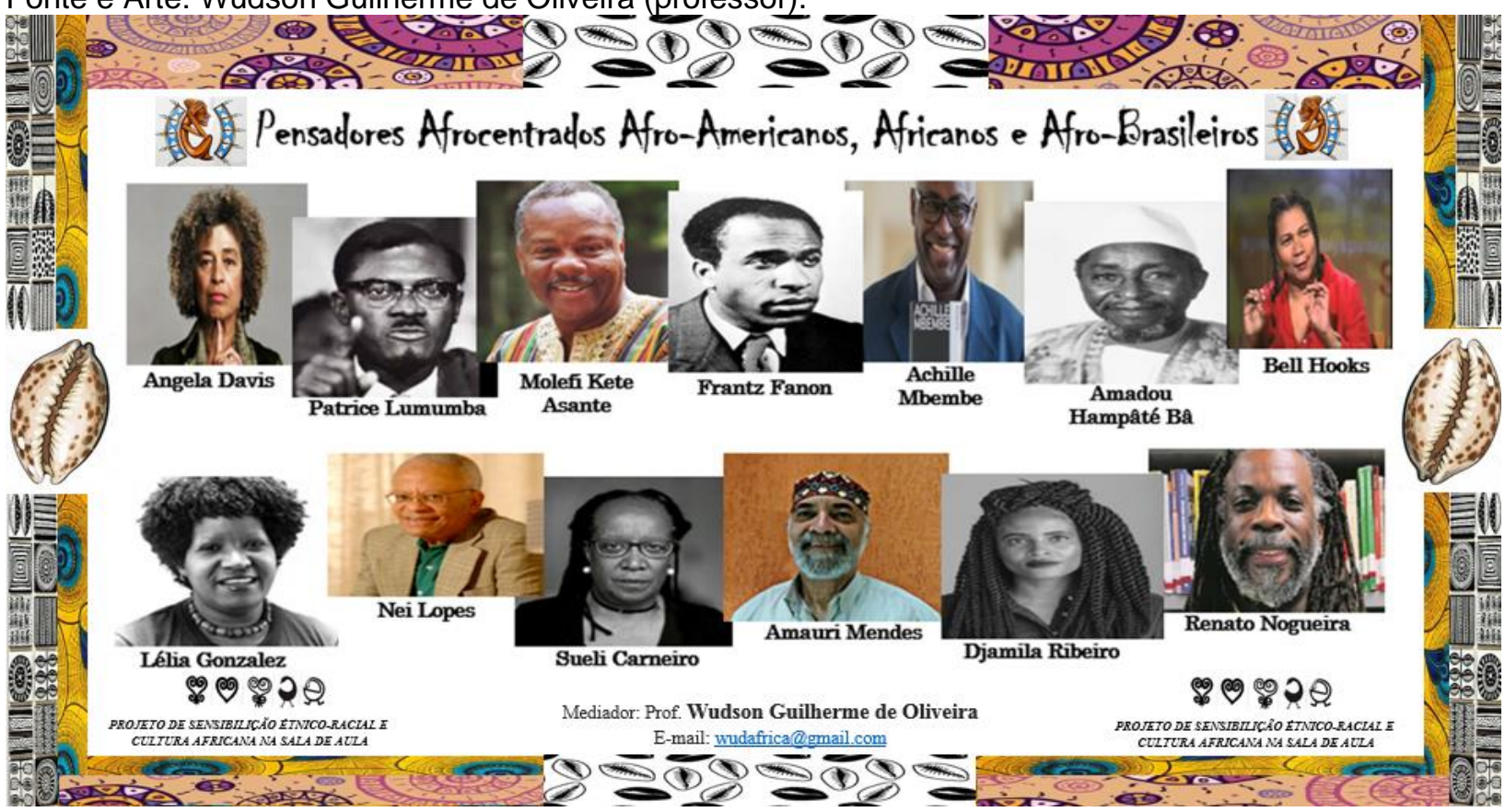

Amparados na democracia, a partir de sorteios foram surgindo "Grupos de Trabalhos", para realizarem pesquisas étnico-raciais sobre os seguintes

14 É mestra em Filosofia Política pela Unifesp, colunista do jornal Folha de São Paulo e foi secretária adjunta de Direitos Humanos e Cidadania do município de São Paulo. Coordena a coleção Feminismos Plurais da Editora Pólen.

15 Ensaísta, psicólogo e líder revolucionário na Argélia, desenvolveu reflexões políticas importantes a respeito da descolonização. Nascido na Martinica e falecido nos Estados Unidos. Escreveu em 1954, "Pele negra, máscaras brancas", um estudo sobre a psicologia dos negros antilhanos.

${ }^{16}$ Cientista Social afro-americano e um dos criadores da filosofia do afrocentrismo, também é autor de outros livros, de Afrocentricity: the theory of social change (1980), African culture: the rhythms of unity (1985) entre outros.

17 Doutor em Filosofia e professor da Universidade Federal Rural do Rio de Janeiro (UFRRJ) e responsável pelo Grupo de Pesquisa Afroperspectivas, Saberes e Interseções (AFROSIN) e autor de vários livros. 
pensadores afrocentrados destacados: Achille Mbembe ${ }^{18}$, Amadou Hampâté Bâ $^{19}$, Amauri Mendes ${ }^{20}$, Angela Davis ${ }^{21}$, Bell Hooks ${ }^{22}$, Djamila Ribeiro, Frantz Fanon, Lélia Gonzalez ${ }^{23}$, Molefi Kete Asante, Nei Lopes ${ }^{24}$, Patrice Lumumba ${ }^{25}$, Renato Nogueira, Sueli Carneiro ${ }^{26}$ entre outros pensadores modernos africanos, afro-americanos e afro-brasileiros, que dialogam com regionalismo, identidade e língua.

No decorrer de todo o $1^{\circ}$ e $2^{\circ}$ Bimestre, em semanas alternadas, foram proporcionadas aos Alunos (as), os saberes do Ensino de Filosofia de acordo com as exigências curriculares do "Complexo Educacional Laudelina de Campos Mello "Nina, lutas e conquistas no Brasil'", e na seguinte os conteúdos afrocentrados com "Aulas/Oficinas" e apresentações dos "Grupos de Trabalhos", onde os (as) Alunos (as) apresentaram suas pesquisas das mais diversas maneiras, entre elas destacamos a apresentação do "Grupo de Trabalho" que pesquisou sobre o pensador Amadou Hampâté Bâ, onde apresentaram aos Alunos (as) observadores, as suas pesquisas (des)colonizadas com figurinos e adereços inspirados nos saberes Griot ${ }^{27}$ e nas Histórias e Culturas Africanas e Afro-brasileiras.

\footnotetext{
${ }^{18}$ É professor de Ciência Política e História na Universidade de Witwatersrand, em Joanesburgo, referência na área dos estudos pós-coloniais e um dos pensadores contemporâneos mais políticos e ativo, tem extensa obra publicada sobre história política africanas, na qual explora os temas sobre o poder e a violência.

19 Filósofo, historiador e escritor, natural da República do Mali, trabalhava para que as culturas orais africanas fossem reconhecidas mundialmente, onde apresentou a público belos textos sobre essas cultura.

${ }^{20}$ Doutor em Ciências Sociais e professor da UFRRJ, tem vastas publicações sobre as Relações Raciais.

21 Escritora, filósofa e ativista política afro-americana.

22 É professora, ativista e escritora. Possui publicações que propõe uma pedagogia antissexista e libertária.

${ }^{23}$ Filosofa, antropóloga e escritora brasileira. Mestre em Comunicação Social e doutora em Antropologia.

${ }^{24}$ Filósofo, escritor e compositor, é autor de várias obras sobre cultura e história afro-brasileira.

${ }^{25}$ Foi líder da independência congolesa e primeiro-ministro da República Democrática do Congo. Foi ligado aos pan-africanistas e profundamente influenciado pelas ideias nacionalistas e anticolonialistas.

${ }^{26}$ Filósofa, pedagoga, advogada, escritora e militante negra e líder feminista.

27 Termo do vocabulário franco-africano, criado na época colonial para designar o narrador, cantor, cronista e genealogista que, pela tradição oral, transmite a história de personagens e famílias importantes das quais, em geral, está a serviço.
} 
Vale ressaltar, que nas "Aulas/Oficinas", a sala de aula estava sempre ambientada com tecidos de temáticas africanas, bonecas (os) negras (os), instrumentos de percussões e Exposições de Livros Africanos, Indígenas e AfroBrasileiros. Todos os livros expostos, tinham como temáticas as questões que dialogavam e/ou colocavam em pauta questões relacionadas à filosofia africana, racismo e aos povos Bantu. Filosofias africanas: uma introdução (LOPES, 2020), Filosofia do ubuntu: valores civilizatórios das ações afirmativas para 0 desenvolvimento (MALOMALO, 2014), Memórias da plantação: episódios de racismo cotidiano (KILOMBA, 2019), Bantos, Malês e identidade negra (LOPES, 2021) entre outros.

Todos expostos com o objetivo de possibilitar aos Alunos (as) um maior contato com estes materiais, e contribuir assim com a cidadania para uma sociedade mais justa. Sempre ao término das apresentações, eram fomentadas as "Rodas de Diálogos" sobre as impressões e desafios encontrados para fazerem as pesquisas, oportunizando trocas de olhares em relação as perspectivas da Filosofia Africana.

Em outros momentos, realizamos leituras de fragmentos de textos, assistimos vídeos e estudamos a partir de lâminas de Slides afrocentrados, sobre as variadas questões que trouxeram variadas temáticas para baile, que serviram de subsídio para as discursões em muitos desdobramentos para a Luta Contra o Racismo no Chão da Escola e fora dela. Onde também foi ofertado aos Alunos (as), saberes sobre a "Influência dos Povos Bantu em nossa sociedade", como forma de (Des)colonizarem os Olhares Eurocêntricos, Racistas, Etnocêntricos, Xenofóbicos, Intolerantes, Machistas, Homofóbicos entre outros, com o intuito de disseminar o respeito ao próximo independentemente da sua cultura, gênero e etnia.

Apresentamos aos Alunos (as) lâminas de Slides sobre os "Povos Bantu", que tem diversos entendimentos entre eles, uma grande proporção dos habitantes da terça parte meridional do continente africano, dos limites marítimos nigero-cameruniana, no Oeste, até a fronteira litorânea somálio-queniano, no 
Leste, a partir desta extremidade até a proximidade de Port-Elizabeth, no Sul, se fala línguas estreitamente semelhantes, intituladas línguas Bantu.

É basilar considerar sobretudo, que também é um "grande conjunto de povos africanos disseminados do centro para o leste, sul e sudeste do continente. Falantes de línguas semelhantes no Congo, em Angola, na Tanzânia, em Moçambique, na África do Sul” (LOPES, 2008, p. 31).

Figura 4. Slide Sobre a migração dos Povos Bantu no continente africano.

Fonte: The Nystrom Atlas of Word History.Arte: Wudson Guilherme de Oliveira (professor).

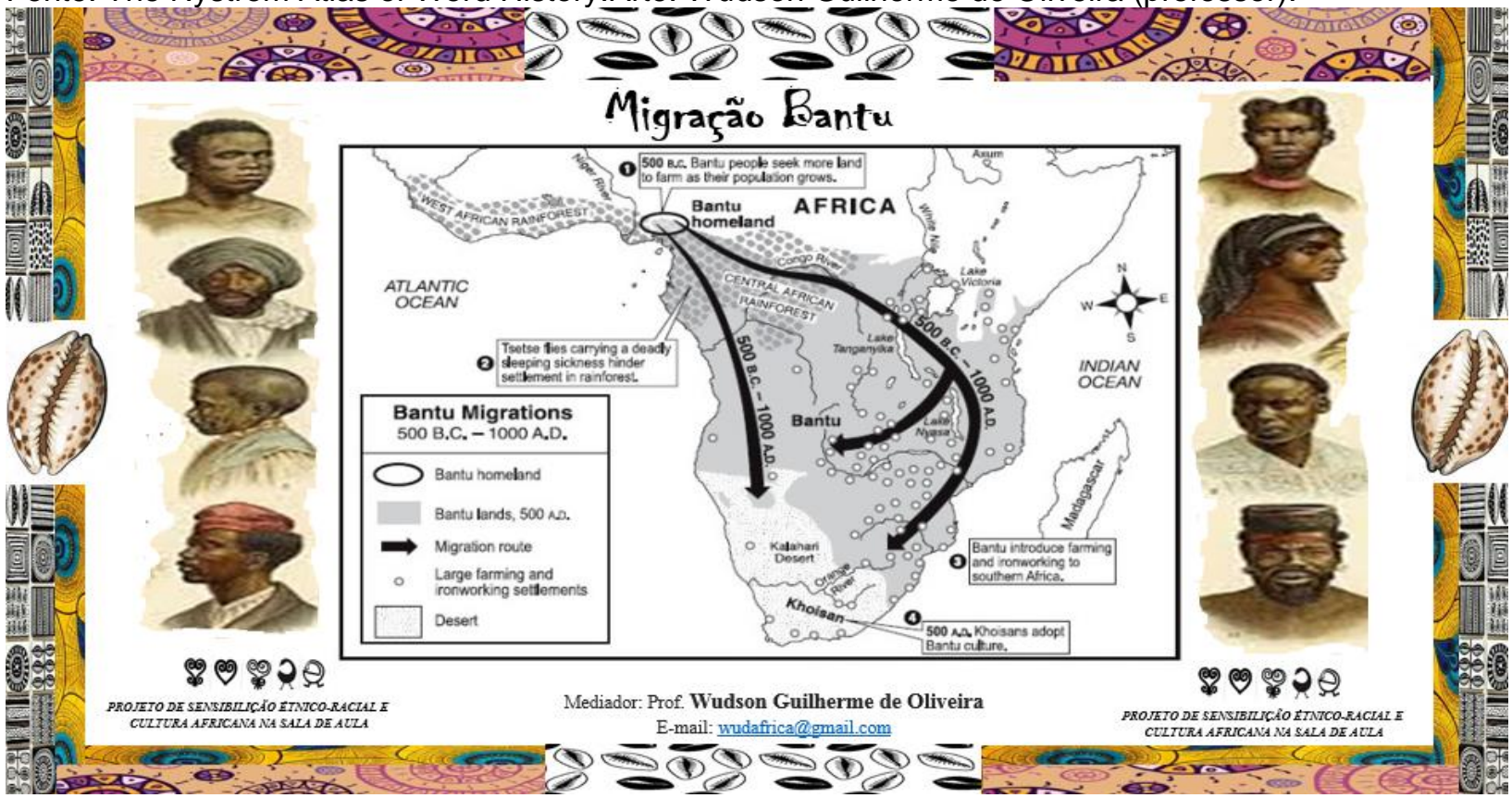

O "Bantu" também se refere a um tronco linguístico que se iniciou com os bantufonos conforme Bruna Marques e Renato Nogueira (2013) afirmam:

Bantufonos diz respeito ao conjunto de povos falantes, isto é, a ênfase está nas línguas que mais de 400 povos falam, neste caso usamos o termo bantu como plural ou estrutura linguística basilar que associada ao termo fonos designa bantufonos, conjunto de povos falantes de idioma bantu. Banto se refere a um povo específico, ênfase no aspecto cultural. Por exemplo, na frase: "esse costume de cuidar das crianças numa família extensa que envolve avós e tias é banto". Ora podemos perceber isso entre no povo Herero que vive no sul de Angola e norte da Namíbia e na região norte da África do Sul entre os zulus. O povo Herero e o povo Zulu têm culturas próprias e específicas; mas, são, em termos afrocentrados, culturalmente de raiz banto (MARQUES e NOGUEIRA, 2013, p. 151). 
Esses parâmetros, é possível observar que o Bantu é na verdade, bem mais que um grupo étnico estabelecido, este conjunto de línguas aparentadas, reúnem variados conjuntos de pessoas que compartilham um mesmo tronco linguístico trivial, onde abraçam mais de quatrocentas variações plurais, vindas de um mesmo antepassado, intitulada como protobanta "O protobanto era falado em uma região fronteiriça no plano ecológico, dispondo portanto de um meio assaz rico, conquanto pudessem dele usufruir os seus habitantes" (LWANGALUNYIIGO; VANSINA, 2010, p 182).

Nos séculos XVI e XIX, milhões de corpos africanos vindos dos territórios Bantu, atravessaram o Atlântico de forma forçada amontoados nos tumbeiros, sem objetos pessoais e tendo como destino os portos brasileiros. Porém, esses grupos que foram obrigados a fazer estas migrações, foram subjugados e transformados em mãos-de-obra escravas especializadas. Mesmo assim, estas etnias trouxeram consigo infinitas bagagens intelectuais e culturais, entre elas as suas estruturas linguísticas (Bantu) e as referências históricas, que resistiram aos impactos e as dificuldades encontradas na sociedade colonial escravocrata portuguesa.

Aqui no Brasil, existe grande predominância da contribuição vocabular dos grupos diásporico falantes das línguas Bantu, notadamente o umbundo, o quimbundo e o quicongo. Porventura é desses idiomas originários do continente africano, que provavelmente eternizaram palavras de tronco linguístico denominado Bantu, onde grande quantidade delas, conhecemos e as utilizamos como, por exemplo: axé28, banzo ${ }^{29}$, boboca, bugiganga, cabaça, cafuné, caçula, cachaça, cochilo, dendêe ${ }^{30}$, dengue, fofoca, fuzuê, ginga, jiló, lemanjá, macumba,

\footnotetext{
28 "Termo de origem iorubá que, em sua acepção filosófica, significa a força que permite a realização da vida, que assegura a existência dinâmica, que possibilita os acontecimentos e as transformações" (LOPES, 2011, p. 146).

${ }^{29}$ Estado psicopatológico, espécie de nostalgia com depressão profunda, quase sempre fatal, em que caíam alguns africanos escravizados nas Américas (LOPES, 2011, p. 181).

30 Denominação do fruto do dendezeiro e, por extensão, do óleo extraído desse fruto, também chamado azeite de dendê (LOPES, 2011, p. 445).
} 
moleque, Oxalá, orixá, pururuca, quiabo, quilombo ${ }^{31}$, quitanda ${ }^{32}$, samba, sopapo, sunga, tagarela, toco, zangado, Zumbi e milhares de outras palavras influenciaram de modo positivo a língua portuguesa no Brasil e a cultura dos Povos Bantu ainda invisibilizada em nossa sociedade.

Figura 5. Slide com palavras da linguística Bantu incorporada no português brasileiro.

Arte: Wudson Guilherme de Oliveira (professor).

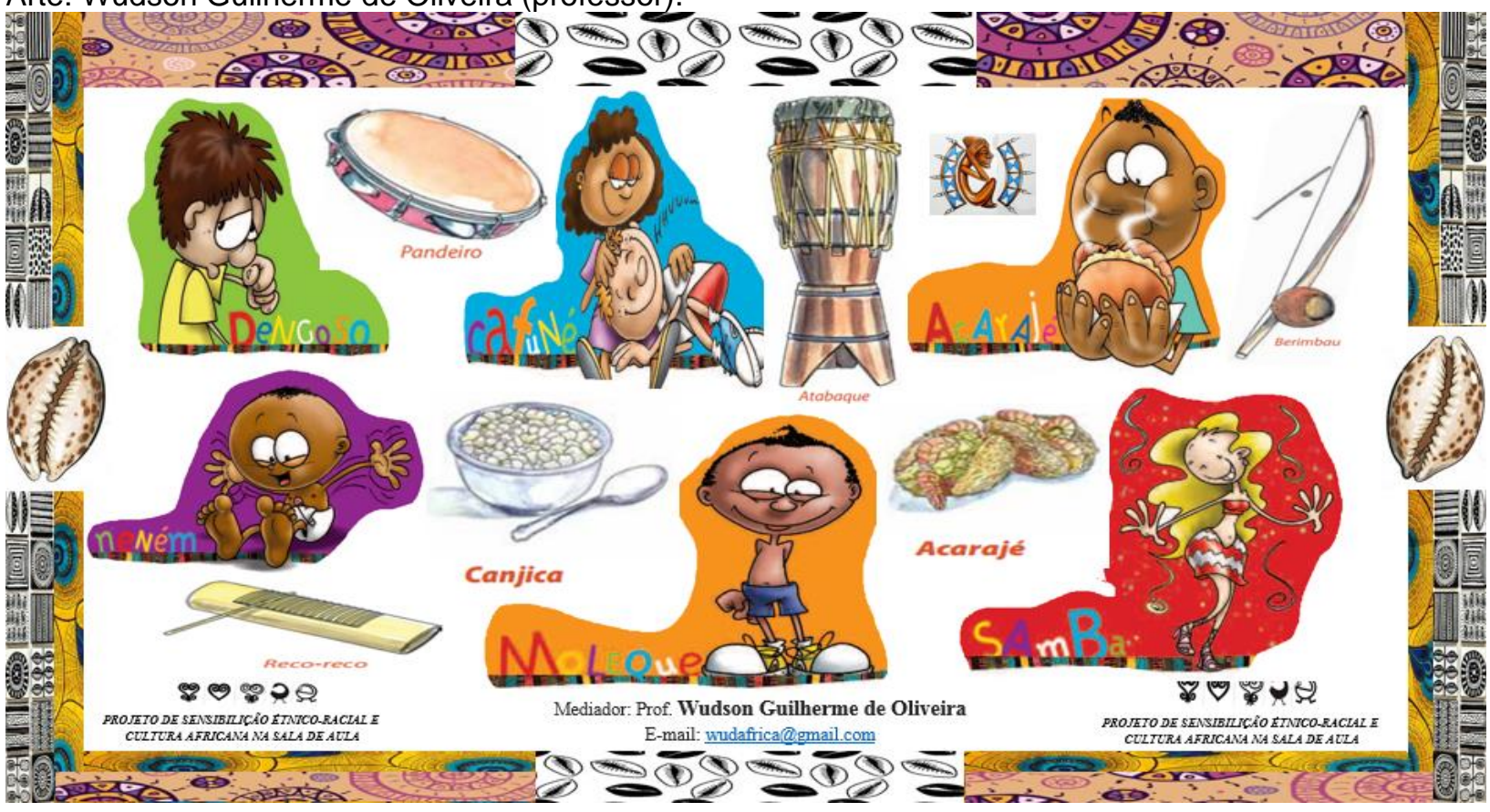

Todos os saberes inspirados na ação pedagógica foram experiências inovadoras para muitos dos Alunos (as), onde desmistificaram questões racistas e estereotipadas, muitas vezes vistas como verdades absolutas por alguns, em relação a História e Cultura dos Africanos, dos Grupos Indígenas e dos Afrobrasileiros.

\section{CONSIDERAÇÕES FINAIS}

Conclui-se que dialogar com as reflexões dos Filósofos (as) Africanos (as) Afro-americanos (as) e Afro-Brasileiros (as) à partir da afroperspectiva da

${ }^{31}$ Aldeamento de escravizados foragidos.

32 "Loja ou tabuleiro em que se vendem hortaliças, legumes, ovos etc., bem como produtos da pastelaria caseira. Também, biscoitos, bolos e doces expostos em tabuleiro" (LOPES, 2011, p. 1082). 
Filosofia Africana, nas "Aulas/Oficinas" e com a importância do protagonismo das contribuições linguísticas e culturais dos Povos Bantu em nossa sociedade, e história do passado e do presente, bem como a importância de potencializar uma educação transgressora para a implementação das Leis Federais 10.6339/03 e 11.645/08, para a luta a favor de uma Educação Étnico-Racial plural no "Complexo Educacional Laudelina de Campos Mello "Nina, lutas e conquistas no Brasil"'. Foi e é, sem dúvidas uma forma potente de dinamizar as Relações Raciais no Chão da Escola.

A escola diferentemente do que muitas pessoas ainda pensam, é a instituição que deve sempre tomar providências cabíveis e emergenciais, com relação aos entraves gerados pelo Bullying e o Racismo. Pois sabemos que nem sempre encontramos nestes espaços de saberes, comprometimentos com as questões das Lei Federais 10.639/03 e 11.645/08.

As instituições de ensino tem o dever de planejar estratégias e atividades, que dialoguem com uma educação igualitária, para assim conscientizar Alunos (as), Professores, Coordenadores, Equipe da Escola, Pais, Responsáveis e toda a Comunidade Escolar, em prol da oportunidade de um conhecimentos (Des)colonizador.

Suponhamos que somente com ações antirracistas, transgressoras e decoloniais cotidianas, no Chão da Escola, será possível restringir o Racismo e as suas ramificações. Pois a luta antirracista é uma luta de todos (as) independentemente da etnia. 


\section{REFERÊNCIAS}

ARAUJO, Edna Maria de. TOLENTINO, Adivânia Nogueira. SILVA, Ananda Catharina Azevedo. Saúde da população negra: política nacional de saúde, avaliações e reflexões sobre suas diretrizes. In: KOMINEK, Andrea Maila Voss; VANALI, Ana Crhistina (Orgs.) Roteiros temáticos da diáspora: caminhos para o enfrentamento ao racismo no Brasil. Porto Alegre, RS: Editora Fi, 2018, p. 243-264.

ASANTE, Molefi Kete. Afrocentricidade: notas sobre uma posição disciplinar. In NASCIMENTO, Elisa Larkin. Afrocentricidade: uma abordagem epistemológica inovadora. Tradução Carlos Alberto Medeiros. São Paulo: Selo Negro, 2009, p. 93-110.

BEAUDOIN, Marie-Nathalie e TAYLOR, Maurreen. Bullying e Desrespeito: como acabar com essa cultura na escola. Porto Alegre: Artmed, 2006.

BRASIL. CNE. Parecer n. 03/2004. Diretrizes curriculares nacionais para a educação das relações étnico-raciais e para o ensino de história e cultura afro-brasileira e africana. Brasília, 2004.

BRASIL. Orientações e Ações para Educação das Relações Étnico-Raciais. - Brasília: SECAD, 2006, p. 219.

BRASIL. Plano Nacional de Implementação das Diretrizes Curriculares Nacionais para a Educação das Relações Étnico-raciais e para o Ensino de História e Cultura Afro-brasileira e Africana, 2009.

CRENSHAW, Kimberlé Williams. Documento para 0 encontro de especialistas em aspectos da discriminação racial relativos ao gênero. Estudos Feministas. Ano 10 vol. 1, 2002. Disponível em <http://www.scielo.br/pdf/ref/v10n1/11636.pdf > Acesso em: 17 set. 2021.

CRENSHAW, Kimberlé Williams. Mapping the Margins: Intersectionality, Identity Politics, and Violence Against Women of Color. Stanford Law Review 43(6), 1991.

FANON, Frantz. Pele negra, máscaras brancas. Tradução de Renato da Silveira. Salvador: EdUFBA, 2008.

GOMES, Joaquim B. Barbosa. Ações afirmativas \& princípios constitucional da igualdade no brasil. Rio de Janeiro, São Paulo. 2001.

GOMES, Nilma Lino. Alguns termos e conceitos presentes no debate sobre relações raciais no Brasil: uma breve discussão. 2010. Disponível em: < https://www.geledes.org.br/wp-content/uploads/2017/03/Alguns-termos-e- 
conceitos-presentes-no-debate-sobre-Rela\%C3\%A7\%C3\%B5es-Raciais-noBrasil-uma-breve-discuss\%C3\%A3o.pdf. > Acessado em 20 de Julho de 2021

GOMES, Nilma Lino. Educação, identidade negra e formação de professores/as: um olhar sobre o corpo negro e o cabelo crespo - Educação e Pesquisa, São Paulo, Volume 29, n. 1 jan/fev. 2003.

GOMES, Nilma Lino. O movimento negro educador: saberes construídos nas lutas por emancipação. Petrópolis, RJ: Vozes, 2017.

HALL, Stuart. Da diáspora - Identidades e mediações culturais. Belo Horizonte/Brasília: UFMG/Unesco, 2003.

HOOKS, Bell. Ensinando a transgredir: a educação como prática da liberdade. Tradução de Marcelo Brandão Cipolla. 2. ed. São Paulo: Editora WMF Martins Fontes, 2017, p. 56.

KILOMBA, Grada. Memórias da plantação: episódios do racismo cotidiano. Tradução de Jess Oliveira. Rio de Janeiro: Cobogó, 2019.

LOPES, Nei. Bantos, malês e identidade negra. $4^{\text {a }}$ ed. - Belo Horizonte: Autêntica, 2021.

LOPES, Nei. Enciclopédia brasileira da diáspora africana. São Paulo: Selo Negro, 2011.

LOPES, Nei. SIMAS, Luiz Antônio. Filosofias africanas: uma introdução. $2^{a}$ ed. - Rio de Janeiro: Civilização Brasiliense, 2020.

LOPES, Nei. História e cultura africana e afro-brasileira. Barsa Planeta, 2008.

LWANGA-LUNYIIGO, Samwiri \& VANSINA, Jan. Os povos falantes de banto e a sua expansão. In: História Geral da África, Volume III: África do século VII ao X. Brasília: UNESCO, Secad/MEC, UFSCar, 2010, p 182.

MALOMALO, Bas'llele. Filosofia ubuntu: valores civilizatórios das ações afirmativas para o desenvolvimento. Curitiba, PR: CRV, 2014.

MALOMALO, Bas'llele. Uma agenda pan-africanista na década internacional de afrodescendentes. In: KOMINEK, Andrea Maila Voss; VANALI, Ana Crhistina (Orgs.) Roteiros temáticos da diáspora: caminhos para o enfrentamento ao racismo no Brasil. Porto Alegre, RS: Editora Fi, 2018, p. 467-499.

MARQUES, Bruna. NOGUEIRA, Renato. Um olhar afro-centrado sobre os bantos: o perfil étnico dos aportados no Rio de Janeiro (1790-1800). In: BERINO, 
Aristóteles. (org.). Diversidade Étnico-Raciais e Educação Brasileira Seropédica, UFRRJ: Evangraf, 2013, p. 147-169.

NETO, Francisco Lima. Laudelina: Laudelina de Campos Melo. Campinas, SP: Editora Mostarda, 2021.

NETO, Godofredo de Oliveira. Cruz e Sousa: o poeta alforriado. Rio de Janeiro: Garamond, 2010.

NOGUEIRA, Renato. O ensino de filosofia e a Lei 10.639. Rio de Janeiro: Pallas: Biblioteca Nacional, 2014.

NOGUEIRA, Renato. Ubuntu como modo de existir: Elementos gerais para uma ética afroperspectivista. Revista da ABPN. v. 3, n. 6. nov. 2011 - fev. 2012, p. 147-150.

OLIVEIRA, Wudson Guilherme de. Diálogos sobre educação étnico-raciais em prol da campanha dos 21 dias de ativismo contra o racismo. In: XAVIER, Leila da Silva. LACERDA, Luciene da Silva e OLIVEIRA, Luiz Fernandes (Orgs). 21 Dias de ativismo contra o racismo. Rio de Janeiro: Editora Selo Novo, 2018, pp. 103-116.

RIBEIRO, Djamila. O que é lugar de fala? São Paulo: Pólen, 2019. Coleção Feminismos Plurais.

SOVIK, Liv. Aqui ninguém é branco: hegemonia branca e media no Brasil. In: WARE, Vron (Org). Branquidade: identidade branca e multiculturalismo. Tradução de Vera Ribeiro. Rio de Janeiro: Garamond, 2004, pp. 363-386.

WALSH, Catherine. Pedagogias Decoloniais: práticas insurgentes de resistir, (re)existir y (re)vivir. Tomo I Serie Pensamiento Decolonial. Equador: Editora Abya Yala, 2013. 